\title{
Accompanied versus unaccompanied walking for continuous oxygen saturation measurement during 6-min walk test in COPD: a randomised crossover study
}

\author{
Thomas F. Riegler $\mathbb{D}^{1,2}$, Anja Frei ${ }^{3}$, Sarah R. Haile $\mathbb{D}^{3}$ and Thomas Radtke $\mathbb{C}^{3}$
}

${ }^{1}$ Berner Reha Zentrum AG, Heiligenschwendi, Switzerland. ${ }^{2}$ Institute for Physiotherapy, Zurich University of Applied Sciences, Zurich, Switzerland. ${ }^{3}$ Epidemiology, Biostatistics and Prevention Institute, University of Zurich, Zurich, Switzerland.

Corresponding author: Thomas F. Riegler (thomasf.riegler@gmail.com)

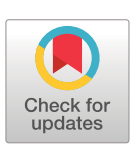

Copyright @The authors 2021

This version is distributed under the terms of the Creative Commons Attribution NonCommercial Licence 4.0. For commercial reproduction rights and permissions contact permissions@ersnet.org

This article has supplementary material available from openres.ersjournals.com

ClinicalTrials.gov identifier: NCT04033783. Ethical approval number: 2019-00827.

Received: 7 Dec 2020

Accepted after revision: 13 March 2021

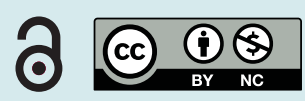

Shareable abstract (@ERSpublications)

Accompanied walking during a 6MWT versus unaccompanied walking results in shorter walked distance (mean difference $-9.1 \mathrm{~m}, 95 \% \mathrm{Cl}-13.9--4.3 \mathrm{~m}$ ). No differences in nadir $\mathrm{S}_{\mathrm{pO}_{2}}$ or oximetry artefacts were noted between accompanied and unaccompanied walking. https://bit.ly/3tBjfCq

Cite this article as: Riegler TF, Frei A, Haile SR, et al. Accompanied versus unaccompanied walking for continuous oxygen saturation measurement during 6-min walk test in COPD: a randomised crossover study. ERJ Open Res 2021; 7: 00921-2020 [DOI: 10.1183/23120541.00921-2020].

\section{Abstract}

The aim of this study was to determine if there is a difference in 6-min walk test (6MWT) distance when the assessor accompanies the patient to continuously measure peripheral oxygen saturation $\left(S_{\mathrm{pO}_{2}}\right)$ compared to the patient walking unaccompanied.

We conducted a randomised crossover study to evaluate the impact of the assessor walking with the

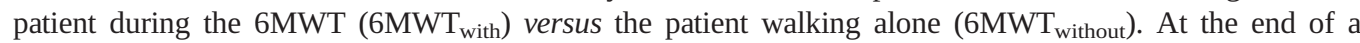
pulmonary rehabilitation programme, each patient performed two 6MWTs in random order and separated by a 30 -min rest.

49 patients with chronic obstructive pulmonary disease (COPD) (Global Initiative for Obstructive Lung Disease classification II-IV) were included. In a regression model adjusting for period and subject, accompanying the patient resulted in a lower walking distance (mean difference $-9.1 \mathrm{~m}, 95 \% \mathrm{CI}-13.9--4.3$, $\mathrm{p}=0.0004$ ). Notably, six patients walked more than $30 \mathrm{~m}$ farther (minimal important difference) in one of the two conditions ( $6 \mathrm{MWT} \mathrm{T}_{\text {with }}: \mathrm{n}=1,6 \mathrm{MWT}_{\text {without }}: \mathrm{n}=5$ ). There were no between-sequence-group differences in heart rate, dyspnoea, leg fatigue and $S_{\mathrm{pO}_{2}}$. The median (interquartile range) number and duration of $S_{\mathrm{pO}_{2}}$ signal artefacts were high but not different between the experimental conditions (6MWT with: 17 (4-24), $34 \mathrm{~s}$ (7-113 s); 6 MWT $_{\text {without: }} 11$ (3-26), 24 s (4-62 s)).

At a study population level, we observed a statistically significant difference in 6MWT distance between the two experimental conditions; however, the magnitude of difference was small and may not be clinically relevant. Nevertheless, in a clinical setting, unaccompanied walking resulted in a substantially higher walking distance in individual patients, pointing towards strictly standardised testing methodology, in particular in pre-post study designs.

\section{Introduction}

The 6-min walk test (6MWT) is a field walking test to assess functional exercise capacity [1]. It is a widely used functional capacity test to evaluate a person's physical fitness, to assess effects of interventions such as rehabilitation programmes and for prognostic purposes [2]. The test is commonly used to measure the lowest peripheral oxygen saturation $\left(S_{\mathrm{pO}_{2}}\right)$ during self-paced exercise [3]. Exercise-induced hypoxaemia is frequently observed in patients with pulmonary disorders $[4,5]$ and the lowest $S_{\mathrm{pO}_{2}}$ does not necessarily occur at the end of the test [6, 7]. Moreover, the extent of oxygen desaturation is important for determining the indication for supplemental oxygen during daily life activities and exercise therapy [4], and to gain indicators for the prognosis in chronic obstructive pulmonary disease (COPD) [8]. 
In 2002, the American Thoracic Society published a technical standard on the 6MWT suggesting that the assessor must not walk with the patient [9]. In an update published in 2014 by the European Respiratory Society and the American Thoracic Society, the document highlights the importance of the continuous measurement of $S_{\mathrm{pO}_{2}}$ during the 6MWT in pulmonary disorders [1]. Therefore, it has been recommended that the assessor accompanies the patient during the 6MWT to continuously monitor $S_{\mathrm{pO}_{2}}$ (i.e. to be able to capture the lowest (nadir) value during the test) [1].

Precise standardisation of testing methodology is of critical importance when conducting a 6MWT. It has been shown that small changes in the testing methodology (e.g. changes in track length, track layout, supplemental oxygen or verbal instructions) and learning experience due to repeated tests affect 6MWT distance [3, 10-13]. No study has evaluated the impact of the assessor walking behind the patient versus standing aside on the 6MWT distance, the primary outcome measure in a 6MWT test, in people with COPD.

This study was designed to assess the impact of the assessor accompanying the patient compared to the patient walking alone (i.e. unaccompanied) on 6MWT distance and nadir $S_{\mathrm{pO}_{2}}$.

Material and methods

Study design and study subjects

We conducted a randomised crossover trial at the Berner Reha Zentrum AG, a specialised rehabilitation clinic located in Bern, Switzerland.

Patients with COPD and Global Initiative for Chronic Obstructive Lung Disease (GOLD) classification II-IV (forced expiratory volume in $1 \mathrm{~s}\left(\mathrm{FEV}_{1}\right) /$ forced vital capacity $(\mathrm{FVC})<0.7, \mathrm{FEV}_{1}<80 \%$ predicted) were included [14]. We calculated \% predicted values and z-scores for $\mathrm{FEV}_{1}$ and $\mathrm{FVC}$ based on equations by QuANJER et al. [15]. We excluded patients who were physically unable to perform a 6MWT (e.g. owing to unstable cardiac disease) or who were unable to understand the instructions for the 6MWT (e.g. owing to cognitive impairment or insufficient knowledge of the language in which the instructions were given).

The study protocol was approved by the Cantonal Ethics Committee Zurich (2019-00827) and the study was registered at clinicaltrials.gov (NCT04033783).

Patients gave their written informed consent to participate in the study, after they were given at least $24 \mathrm{~h}$ to decide [16]. The recruitment was performed consecutively between September and December 2019. All data were collected in REDCap (Research Electronic Data Capture; Vanderbilt University, Nashville, TN, USA [17]), a secure, web-based application designed to support data capture for research studies, hosted at the Clinical Trials Center at the University Hospital of Zurich.

\section{Randomisation and allocation concealment}

We used simple randomisation (1:1 ratio) to randomly allocate patients into either one of two sequence groups: first assessment $6 \mathrm{MWT}$ with the assessor walking behind the patient $\left(6 \mathrm{MWT}_{\text {with }}\right)$ and second $6 \mathrm{MWT}$ with the patient walking alone $\left(6 \mathrm{MWT}_{\text {without }}\right)$, or vice versa. The randomisation list was created with $\mathrm{R}$ software [18] (coded as $0=$ starting with $6 \mathrm{MWT}_{\text {without }}$ or $1=6 \mathrm{MWT}_{\text {with }} \mathrm{n}=60$ to account for potential dropouts) using the R package blockrand [19]. The list was compiled by a biostatistician (SRH) who was not involved in the study recruitment, randomisation or study-specific assessments. A person not involved in the study implemented the randomisation list into the database (REDCap [17]) to ensure complete concealment of random allocation. Randomisation within REDCap was always performed by the same person, after inclusion and exclusion criteria were evaluated.

6MWT

The 6MWT was performed on a $30 \mathrm{~m}$ floor according to a recent technical standard [1]. All assessments were performed at the end of the inpatient pulmonary rehabilitation programme (1-7 days before leaving the clinic) and supervised by the same assessor (TFR) throughout the entire study. Patients and assessor were not blinded to the experimental condition. All included patients had already performed at least one and up to three 6MWTs prior to the study assessments, thus accounting for possible learning effects [3].

Prior to the study assessments, each patient had at least $1 \mathrm{~h}$ of rest before starting the first allocated walking test. After randomisation, each patient conducted two 6MWTs. Between the two tests, there was a resting phase of 30 min to allow heart rate and $S_{\mathrm{pO}_{2}}$ to reach pre-testing values [1]. Before each 6MWT patients received the standardised instruction for the test as described by Holland et al. [1], which has been translated by our research group into German. Additionally, all 6MWTs were monitored with 
pulse oximetry, using a handheld pulse oximeter (Covidien Nellcor PM10N, Dublin, Ireland). The sensor was attached to the patient's left middle finger and fixed with tape (figure 1a).

In the $6 \mathrm{MWT}_{\text {with }}$, the pulse oximeter was held by the assessor who walked $1 \mathrm{~m}$ behind and did not "pace" the patient, as recommended (figure 1c) [1]. The $6 \mathrm{MWT}_{\text {without }}$ condition was performed without the assessor walking with the patient (i.e. the assessor was standing at the $15 \mathrm{~m}$ mark of the $30 \mathrm{~m}$ test course). In this condition, the pulse oximeter was placed around the trunk of the patient and fixed with a strap (figure 1b). Walking aids and/or supplemental oxygen dose, if needed, were identical during both experimental conditions.

After completion of the two 6MWTs, patients filled out a self-administered questionnaire to report their subjective perception with regards to preferences, velocity and safety during both 6MWTs.

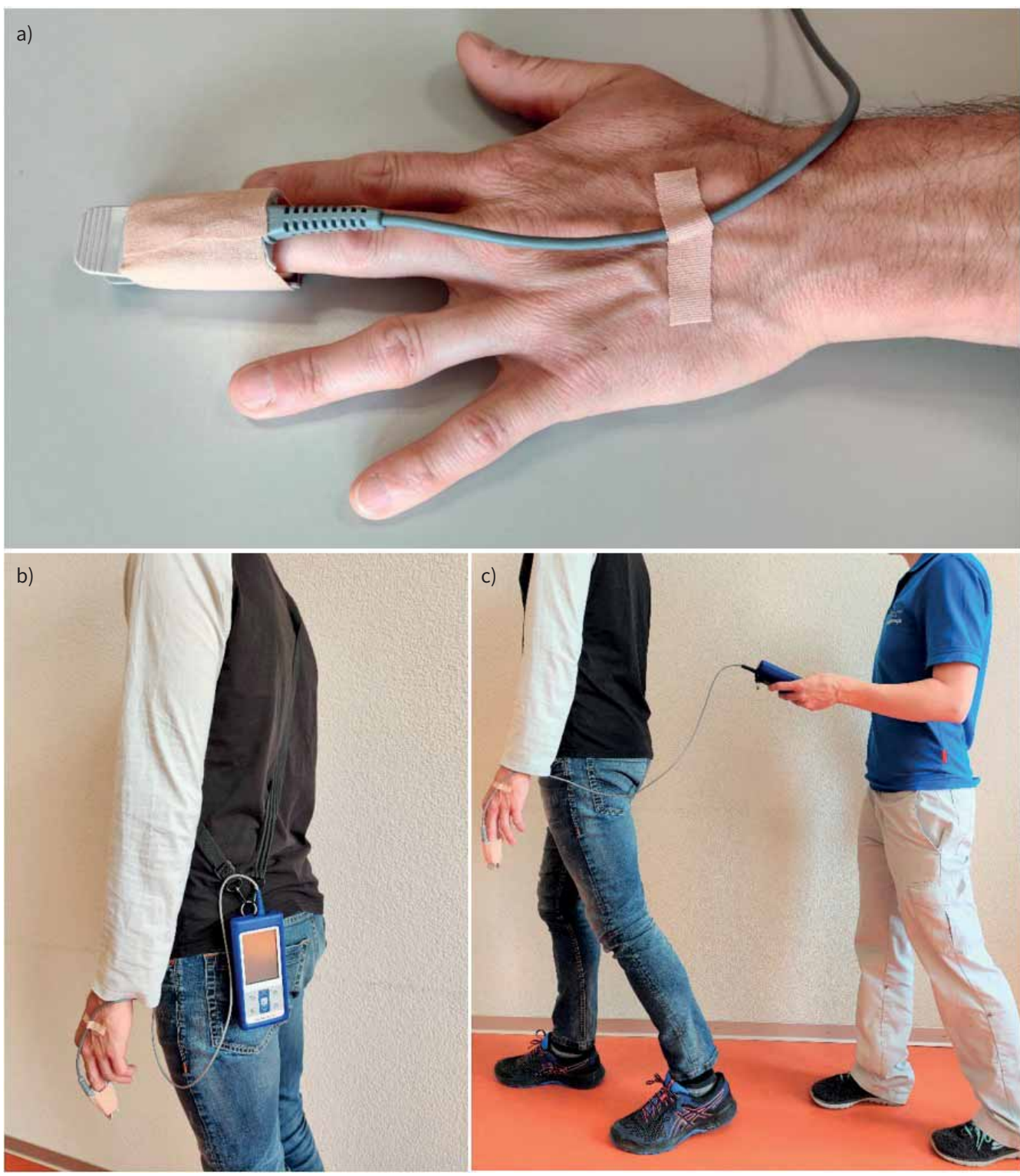

FIGURE 1 Sensor fixation with tape and experimental conditions. a) Sensor fixation with tape. b) 6-min walk test (6MWT) in which the patient walked alone with the pulse oximeter around the trunk $(6 \mathrm{MWT}$ without). c) 6MWT in which the assessor walked behind the patient $\left(6 M W T_{\text {with }}\right)$. 


\section{Analysis}

The sample size calculation was performed using a predefined difference of $30 \mathrm{~m}$ between the 6MWTs under the two conditions, which is the established minimal important difference (MID) for patients with COPD [3]. We assumed a standard deviation of the change scores of the 6MWT of $73 \mathrm{~m}$ [3], which equals an effect size of 0.41 . To achieve a power of $80 \%$ to detect a difference of $30 \mathrm{~m}$ with an assumed standard deviation of $73 \mathrm{~m}, 49$ patients were required, assuming a two-sided significance level of 0.05 . The sample size calculation was performed with G*Power 3.1.9.2 [20].

For the primary endpoint (6MWT distance in metres), a linear regression model adjusting for the experimental condition $\left(6 \mathrm{MWT}_{\text {with }}\right.$ versus $6 \mathrm{MWT}_{\text {without }}$, coded as 1,0$)$, period (first test or second test) and subject was performed [21].

Secondary outcomes were patient-reported perception of different aspects such as feeling of safety, self-perceived influence on gait velocity or interfering factors during the two versions of the 6MWT.

Exploratory outcomes were pre- and post-test heart rate, dyspnoea and leg fatigue (0-10 Borg scale), and pulse oximetry data from the two 6MWTs per subject. Pulse oximetry data were used to quantify measurement artefacts and the lowest $S_{\mathrm{pO}_{2}}$ (nadir value) during the 6MWT. Pulse oximetry data were downloaded as csv data sheets from the pulse oximeter using Nellcor Analytics Tool (version 1.6.0). The lowest $S_{\mathrm{pO}_{2}}$ values were manually corrected, if needed, to obtain the true $S_{\mathrm{pO}_{2}}$ nadir without measurement artefacts. Exploratory outcomes were evaluated using the same adjusted linear regression model as for the primary endpoint.

Statistical analyses were performed using IBM SPSS Statistics version 26.0 [22] and R version 3.6.3 [18].

Results

\section{Patients}

51 patients were included in the study. Of those, 22 patients were randomised to the sequence group $6 \mathrm{MWT}_{\text {with }}$ followed by $6 \mathrm{MWT}_{\text {without }}$ and 29 were randomised to the sequence group $6 \mathrm{MWT}_{\text {without }}$ followed by $6 \mathrm{MWT}_{\text {with }}$. Two patients of the $6 \mathrm{MWT}_{\text {without }}$ then $6 \mathrm{MWT}_{\text {with }}$ group were excluded from the analysis. One patient reported that he had to walk slower on the second 6MWT because of low back pain. The other patient was excluded because of a screening failure (i.e. lung function data did not adhere to inclusion criteria). In total, data from 49 patients were analysed (figure 2) [23].

Baseline characteristics are shown in table 1. Pre- and post-walking test values for heart rate, $S_{\mathrm{pO}_{2}}$ and perceived dyspnoea and leg fatigue are given in supplementary table $\mathrm{S} 1$. Overall, $6 \%(\mathrm{n}=3)$ used a walking aid, 6\% (n=3) used supplemental oxygen (ranging from 1 to $\left.10 \mathrm{~L} \cdot \mathrm{min}^{-1}\right), 37 \%(\mathrm{n}=18)$ used both a walking aid and supplemental oxygen and 51\% $(n=25)$ used neither a walking aid nor supplemental oxygen during the 6MWTs. The used walking aids and oxygen dose were the same during both experimental conditions.

\section{MWT distance}

Walking behind the patient during the 6MWT $\left(6 \mathrm{MWT}_{\text {with }}\right)$ resulted in a shorter walking distance of $-9.1 \mathrm{~m}$ (95\% CI -13.9- -4.3, table 2). On the individual level, with regards the MID, five patients (10\%) walked a distance that was $\geqslant 30 \mathrm{~m}$ longer when walking alone $\left(6 \mathrm{MWT}_{\text {without }}\right)$. In contrast, one patient ( $2 \%$ ) walked a distance that was $\geqslant 30 \mathrm{~m}$ longer when the test was accompanied (supplementary figure S1).

\section{Pulse oximetry: $\mathrm{S}_{\mathrm{PO}_{2}}$ and signal artefacts}

There were no significant differences in $S_{\mathrm{pO}_{2}}$ nadir and pulse oximetry artefacts in absolute numbers and duration between the two experimental conditions (table 2). The median (interquartile range) number and duration of $S_{\mathrm{pO}_{2}}$ signal artefacts were not different between the two experimental conditions $\left(6 \mathrm{MWT}_{\text {with }}\right.$ : 17 (4-24), $34 \mathrm{~s}$ (7-113 s); $6 \mathrm{MWT}_{\text {without: }} 11$ (3-26), $24 \mathrm{~s}(4-62 \mathrm{~s})$ ). The nadir $S_{\mathrm{pO}_{2}}$ during all 6MWTs was in $61-69 \%$ of cases lower than the post-test $S_{\mathrm{pO}_{2}}\left(6 \mathrm{MWT} \mathrm{T}_{\text {with }}\right.$ : 30 out of 49 cases; $6 \mathrm{MWT}_{\text {without }}: 34$ out of 49 cases). Among a total of 98 walking tests, a difference of $\geqslant 3 \%$ between $S_{\mathrm{pO}_{2}}$ post-test and $S_{\mathrm{pO}_{2}}$ nadir values was found for 15 tests (15\%), while a difference of $\leqslant 2 \%$ was observed in 83 tests (85\%).

\section{Patients' perceptions}

Patients' perceptions during the $6 \mathrm{MWT}_{\text {with }}$ are summarised in supplementary table S2.

$59 \%(n=29)$ of patients stated no preference for either of the two 6MWTs, whereas $25 \%(n=12)$ preferred the $6 \mathrm{MWT}_{\text {with }}$ and $16 \%(\mathrm{n}=8)$ preferred the $6 \mathrm{MWT}_{\text {without }}$. 


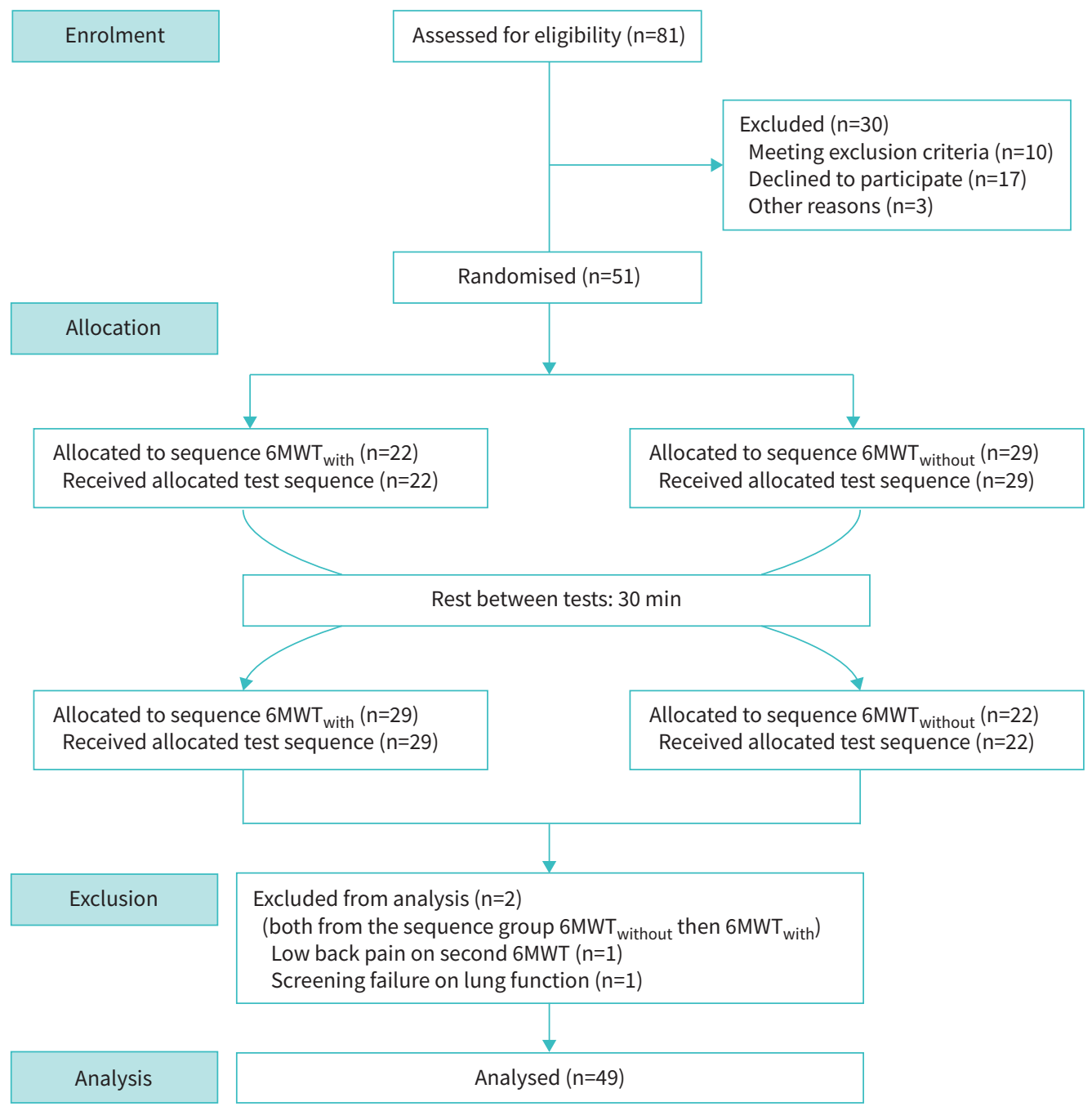

FIGURE 2 Study flow chart. 6MWT: 6-min walk test.

Patients favouring the $6 \mathrm{MWT}_{\text {with }}$ noted "safety and supervision" $(\mathrm{n}=4)$, "less loneliness" (n=1), "easier walking” ( $n=2)$, “test goes by faster" $(n=3)$, "self-induced reminder on breathing technique” $(n=2)$ and "more motivating to walk together" $(\mathrm{n}=2)$ as reasons. Patients preferring the $6 \mathrm{MWT}_{\text {without }}$ reported feeling "more free and having no pressure while walking” ( $\mathrm{n}=4)$, “choosing their own tempo" $(\mathrm{n}=3)$ and "being used to walk alone” $(\mathrm{n}=2)$ as their preferential reasons.

In addition, two patients who reported feeling "stressed" by the assessor accompanying them mentioned the "cable of the pulse oximeter" $(n=1)$, "proximity of the assessor" $(n=1)$ and "feeling a lower velocity of the assessor" ( $\mathrm{n}=1)$ as reasons.

\section{Discussion}

This randomised crossover study investigated the impact of the assessor walking behind the patient compared to the patient walking alone on the distance covered during a 6MWT in people with COPD. We observed a shorter walking distance in the test condition in which the assessor accompanied the patient $\left(6 \mathrm{MWT}_{\text {with }}\right)$ than in the condition in which the patient was walking alone $\left(6 \mathrm{MWT}_{\text {without }}\right)$. No differences between study conditions were observed in nadir $S_{\mathrm{pO}_{2}}$ or the number and duration of signal artefacts during pulse oximetry measurements. The majority of patients had no preference for either test condition.

\section{MWT distance}

In this study, accompanying the patient resulted in a shorter 6MWT distance of $-9.1 \mathrm{~m}$ (95\% CI $-13.9--4.3)$ compared to the patient walking alone. Our data suggest a systematic difference resulting in a 


\begin{tabular}{|c|c|c|c|}
\hline Variable & $6 \mathrm{MWT}_{\text {with }}$ then $6 \mathrm{MWT}_{\text {without }}$ & $6 \mathrm{MWT}_{\text {without }}$ then $6 \mathrm{MWT}_{\text {with }}$ & Total \\
\hline Subjects $n$ & 22 & 27 & 49 \\
\hline Age years & $67 \pm 8$ & $71 \pm 9$ & $69 \pm 9$ \\
\hline \multicolumn{4}{|l|}{ Sex } \\
\hline Female & $9(41)$ & $11(41)$ & $20(41)$ \\
\hline Male & $13(59)$ & $16(59)$ & $29(59)$ \\
\hline \multicolumn{4}{|l|}{ GOLD stage } \\
\hline II & $4(18)$ & $9(33)$ & $13(26)$ \\
\hline III & $11(50)$ & $13(48)$ & $24(49)$ \\
\hline IV & $7(32)$ & $5(19)$ & $12(25)$ \\
\hline $\mathrm{FEV}_{1} \%$ pred & $38 \pm 11$ & $45 \pm 14$ & $42 \pm 13$ \\
\hline FEV $_{1}$ z-score & $-3.7 \pm 0.7$ & $-3.2 \pm 0.9$ & $-3.4 \pm 0.8$ \\
\hline $\mathrm{FEV}_{1} / \mathrm{FVC}$ ratio & $0.47 \pm 0.07$ & $0.49 \pm 0.09$ & $0.48 \pm 0.08$ \\
\hline $\mathrm{FEV}_{1} / \mathrm{FVC}$ ratio z-score & $-3.5 \pm 0.7$ & $-3.1 \pm 0.9$ & $-3.28 \pm 0.8$ \\
\hline 6MWT on admission m & $268 \pm 96$ & $267 \pm 92$ & $267 \pm 96$ \\
\hline \multicolumn{4}{|c|}{ 6MWTs prior to study inclusion } \\
\hline 1 test & $6(27)$ & $8(30)$ & $14(28)$ \\
\hline 2 tests & $9(41)$ & $10(37)$ & $19(39)$ \\
\hline 3 tests & $7(32)$ & $9(33)$ & $16(33)$ \\
\hline
\end{tabular}

shorter 6MWT distance when the assessor walks behind the patient. At a population level, the magnitude of the observed difference of $-9.1 \mathrm{~m}$ is small (about 2-3\% of the total walking distance) and below the well-established MID for the 6MWT [3]. However, at an individual level, we noticed that about 10\% ( $\mathrm{n}=5)$ of the patients walked $\geqslant 30 \mathrm{~m}$ farther when walking alone. In comparison, only one participant walked farther when accompanied. Unfortunately, the authors are not aware of any previous studies assessing the intra-day variability in 6MWT distance in people with (cardio)respiratory diseases that would facilitate the interpretation of the magnitude of observed effects. Numerous studies have investigated the impact of changes in testing methodology on 6MWT distance, e.g. additional verbal encouragement [24], use of different test instructions [13], walking with walking aids [25-30], supplemental oxygen [31-35] or compressed air [36], carrying oxygen devices [35, 37], different track layouts [11, 12] and track lengths [10], which have led to differences in 6MWT distance ranging from $-49.5 \mathrm{~m}$ to $109 \mathrm{~m}$. Considering the huge variability arising from changes in testing methodology, our between-test difference seems small when interpreted at a population level. However, it is unclear to what extent additive or multiplicative interaction could occur when other additional methodological changes are applied. It is important to note that, in contrast to research settings, the risk for methodological changes might be even greater in clinical settings, e.g. when different assessors supervise walking tests.

Pulse oximetry: $\mathrm{S}_{\mathrm{pO}_{2}}$ and signal artefacts

In our study, no differences between the two walking test conditions were observed in nadir $S_{\mathrm{pO}_{2}}$ or the number and duration of signal artefacts during pulse oximetry measurements.

TABLE 2 Differences in walking distance and oxygen saturation between the two experimental conditions

\begin{tabular}{lcccc} 
Outcome & $6 \mathrm{MWT}_{\text {with }}$ & $6 \mathrm{MWT}_{\text {without }}$ & Mean difference & p-value \\
\hline $6 \mathrm{MWT} \mathrm{m}$ & $337.8 \pm 85.7$ & $346.5 \pm 86.4$ & $-9.1(-13.9--4.3)$ & 0.0004 \\
$\mathrm{~S}_{\mathrm{pO}_{2}}$ nadir \% & $85.1 \pm 5.4$ & $85.0 \pm 5.6$ & $0.06(-0.49-0.62)$ & 0.82 \\
$\mathrm{~S}_{\mathrm{pO}_{2}}$ artefact $\mathrm{n}$ & $17(4-24)$ & $11(3-26)$ & $0.60(-3.76-4.96)$ & 0.78 \\
$\mathrm{~S}_{\mathrm{pO}_{2}}$ artefact $\mathrm{s}$ & $34(7-113)$ & $24(4-62)$ & $17.90(-5.45-41.20)$ & 0.13 \\
\hline
\end{tabular}

Data are given as mean \pm SD or median (interquartile range). Mean differences $\left(95 \% \mathrm{Cl}\right.$ ) between $6 \mathrm{MWT}_{\text {with }}$ versus $6 \mathrm{MWT}_{\text {without }}$ and $\mathrm{S}_{\mathrm{pO}_{2}}$ outcomes were analysed with a linear regression model adjusting for the experimental condition, period and subject. $6 \mathrm{MWT}$ : 6-min walk test; $6 \mathrm{MWT}_{\text {with }}$ : assessor walking behind the patient during 6MWT; $6 \mathrm{MWT}_{\text {without: }}$ patient walking alone during $6 \mathrm{MWT} ; \mathrm{S}_{\mathrm{pO}_{2}}$ : peripheral oxygen saturation. 
Oxygen desaturation is common in chronic lung diseases, especially during exercise [4, 5], and the extent of desaturation during a 6MWT can provide important information regarding disease severity, prognosis [8] and supplemental oxygen titration. It must be noted that the lowest $S_{\mathrm{pO}_{2}}$ does not always occur at the end of the 6MWT [6]. This is one reason (among others) that continuous pulse oximetry monitoring during the 6MWT is recommended [1]. In general, pulse oximetry during the 6MWT is a reliable measurement under the condition that a high-quality and stable signal is received [1,3]. Pulse oximeters need the pulse waveform to calculate the correct $S_{\mathrm{pO}_{2}}$ value [38]. In this study, the assessor held the pulse oximeter in order to clearly see the pulse waveforms. To ensure an adequate pulse wave signal we fixed the sensor with tape around the left middle finger and on the back of the hand. However, despite additional fixation we observed a high number and long duration of signal artefacts in each single walking test (table 2). Nonetheless, there were no differences in $S_{\mathrm{pO}_{2}}$ signal artefacts between the two experimental conditions, suggesting that the assessor carrying the pulse oximeter when walking behind the patient did not introduce measurement bias.

We observed differences between the nadir and post-test $S_{\mathrm{pO}_{2}}$ values in 64 out of 98 (65\%) of the 6MWTs. Overall, the differences in $S_{\mathrm{pO}_{2}}$ recordings ranged from $0 \%$ to $12 \%$. In 15 out of 98 tests a $\geqslant 3 \%$ difference between post-test and nadir $S_{\mathrm{pO}_{2}}$ was observed, whereas in 83 out of 98 tests the difference was $\leqslant 2 \%$. Our results indicate little difference between the post-test $S_{\mathrm{pO}_{2}}$ and nadir $S_{\mathrm{pO}_{2}}$. Our data confirm previous studies $[6,7]$ demonstrating differences between nadir $S_{\mathrm{pO}_{2}}$ and post-exercise $S_{\mathrm{pO}_{2}}$ values, underlying the need to continuously monitor $S_{\mathrm{pO}_{2}}$ during the 6MWT [1].

\section{Patients' perceptions}

Most patients did not state a preference for either of the two experimental conditions. If they preferred one condition over the other, it was mostly due to personal preference and experience (e.g. favourably walking alone at home).

Similarly, a majority of the patients did not feel their walking speed was negatively affected by the assessor walking behind them during the test. Slightly more dispersion was observed in the answers concerning if the patients felt driven. However, this contradicts the lower mean walking distance in the $6 \mathrm{MWT}_{\text {with }}$ condition.

Interestingly, one third of patients felt safer when the assessor walked behind them.

\section{Strengths and limitations}

One strength of our study is the randomised crossover design [23], which minimises inter-subject variability and confounding factors. Furthermore, all study assessments were conducted at the end of a pulmonary rehabilitation programme when patients were in stable clinical condition and potential learning effects for the 6MWT were diminished [39]. The latter is supported by the fact that all patients had performed at least one $6 \mathrm{MWT}$ and $72 \%$ of patients had performed two or three walking tests before inclusion into the study.

Limitations of the study include lack of masking of the outcome assessor, which was not possible because of the design. However, all assessments were performed and supervised by the same person and followed a standardised testing protocol, thus lessening measurement bias. With respect to pulse oximetry measurements, we acknowledge that finger probes, compared to forehead sensors, are more prone to inaccurate measurements owing to motion artefacts or poor perfusion of fingertips. Additionally, pulse oximetry devices with Bluetooth connection already exist to assess $S_{\mathrm{pO}_{2}}$ remotely. However, Bluetooth devices may not be readily available in every clinical setting and additional time is required to analyse $S_{\mathrm{pO}_{2}}$ recordings to be able to determine the nadir value. Therefore, the chosen measurement methodology in our study may best reflect the typical clinical setting, in which handheld pulse oximeters are being used.

In conclusion, walking behind the patient during a 6MWT, compared to the patient walking alone, results in a shorter walking distance in the range of -13.9 to $-4.3 \mathrm{~m}$. This difference is considered small but supports the need for strict standardisation of testing methodology, especially in repeated measures study designs, clinical settings and between-group comparisons. 
References

1 Holland AE, Spruit MA, Troosters T, et al. An official European Respiratory Society/American Thoracic Society technical standard: field walking tests in chronic respiratory disease. Eur Respir J 2014; 44: 1428-1446.

2 Holland AE, Spruit MA, Singh SJ. How to carry out a field walking test in chronic respiratory disease. Breathe 2015; 11: 128-139.

3 Singh SJ, Puhan MA, Andrianopoulos V, et al. An official systematic review of the European Respiratory Society/American Thoracic Society: measurement properties of field walking tests in chronic respiratory disease. Eur Respir J 2014; 44: 1447-1478.

4 van Gestel AJR, Clarenbach CF, Stöwhas AC, et al. Prevalence and prediction of exercise-induced oxygen desaturation in patients with chronic obstructive pulmonary disease. Respiration 2012; 84: 353-359.

5 Jenkins S, Čečins N. Six-minute walk test: observed adverse events and oxygen desaturation in a large cohort of patients with chronic lung disease. Intern Med J 2011; 41: 416-422.

6 Fiore C, Lee A, McDonald C, et al. Should oxyhaemoglobin saturation be monitored continuously during the 6-minute walk test? Chron Respir Dis 2011; 8: 181-184.

7 Chuang M-L, Lin I-F, Chen S-P. Kinetics of changes in oxyhemoglobin saturation during walking and cycling tests in COPD. Respir Care 2014; 59: 353-362.

8 Takigawa N, Tada A, Soda R, et al. Distance and oxygen desaturation in 6-min walk test predict prognosis in COPD patients. Respir Med 2007; 101: 561-567.

9 ATS Committee on Proficiency Standards for Clinical Pulmonary Function Laboratories. ATS statement: guidelines for the six-minute walk test. Am J Respir Crit Care Med 2002; 166: 111-117.

10 Beekman E, Mesters I, Hendriks EJM, et al. Course length of 30 metres versus 10 metres has a significant influence on six-minute walk distance in patients with COPD: an experimental crossover study. J Physiother 2013; 59: 169-176.

11 Bansal V, Hill K, Dolmage TE, et al. Modifying track layout from straight to circular has a modest effect on the 6-min walk distance. Chest 2008; 133: 1155-1160.

12 Sciurba F, Criner GJ, Lee SM, et al. Six-minute walk distance in chronic obstructive pulmonary disease. Am J Respir Crit Care Med 2003; 167: 1522-1527.

13 Weir NA, Brown AW, Shlobin OA, et al. The influence of alternative instruction on 6-min walk test distance. Chest 2013; 144: 1900-1905.

14 Global Initiative for Chronic Obstructive Lung Disease. Global Strategy for the Diagnosis, Management and Prevention of Chronic Obstructive Lung Disease. www.goldcopd.org. Date last accessed: April 17, 2020.

15 Quanjer PH, Stanojevic S, Cole TJ, et al. Multi-ethnic reference values for spirometry for the 3-95-yr age range: the global lung function 2012 equations. Eur Respir J 2012; 40: 1324-1343.

16 Paterick TJ, Carson GV, Allen MC, et al. Medical informed consent: general considerations for physicians. Mayo Clin Proc 2008; 83: 313-319.

17 Harris PA, Taylor R, Thielke R, et al. Research Electronic Data Capture (REDCap) - a metadata-driven methodology and workflow process for providing translational research informatics support. J Biomed Inform 2009; 42: 377-381.

18 R Core Team. R: A Language and Environment for Statistical Computing. Vienna, Austria: R Foundation for Statistical Computing; 2018. www.R-project.org/

19 Snow G. Randomization for Block Random Clinical Trials. 2020. https://CRAN.R-project.org/ package=blockrand. Date last accessed: November 22, 2020.

20 Faul F, Erdfelder E, Lang A-G, et al. G*Power 3: a flexible statistical power analysis program for the social, behavioral, and biomedical sciences. Behav Res Methods 2007; 39: 175-191.

21 Senn SS. Cross-over trials in clinical research. 2nd edition. Hoboken, NY, Wiley; 2002. p364.

22 IBM SPSS Statistics for Windows. Armonk, IBM Corp., 2019.

23 Dwan K, Li T, Altman DG, et al. CONSORT 2010 statement: extension to randomised crossover trials. BMJ 2019; 366: 14378.

24 Guyatt GH, Pugsley SO, Sullivan MJ, et al. Effect of encouragement on walking test performance. Thorax 1984; 39: 818-822.

25 Gupta R, Goldstein R, Brooks D. The acute effects of a rollator in individuals with COPD. J Cardiopulm Rehabil 2006; 26: 107-111.

26 Honeyman P, Barr P, Stubbing DG. Effect of a walking aid on disability, oxygenation, and breathlessness in patients with chronic airflow limitation. J Cardiopulm Rehabil 1996; 16: 63-67.

27 Probst VS, Troosters T, Coosemans I, et al. Mechanisms of improvement in exercise capacity using a rollator in patients with COPD. Chest 2004; 126: 1102-1107.

28 Roomi J, Yohannes AM, Connolly MJ. The effect of walking aids on exercise capacity and oxygenation in elderly patients with chronic obstructive pulmonary disease. Age Ageing 1998; 27: 703-706.

29 Solway S, Brooks D, Lau L, et al. The short-term effect of a rollator on functional exercise capacity among individuals with severe COPD. Chest 2002; 122: 56-65. 
30 Vaes AW, Annegarn J, Meijer K, et al. The effects of a 'new' walking aid on exercise performance in patients with COPD: a randomized crossover trial. Chest 2012; 141: 1224-1232.

31 Davidson AC, Leach R, George RJ, et al. Supplemental oxygen and exercise ability in chronic obstructive airways disease. Thorax 1988; 43: 965-971.

32 Fujimoto K, Matsuzawa $\mathrm{Y}$, Yamaguchi S, et al. Benefits of oxygen on exercise performance and pulmonary hemodynamics in patients with COPD with mild hypoxemia. Chest 2002; 122: 457-463.

33 Rooyackers JM, Dekhuijzen PN, Van Herwaarden CL, et al. Training with supplemental oxygen in patients with COPD and hypoxaemia at peak exercise. Eur Respir J 1997; 10: 1278-1284.

34 Jolly EC, Di Boscio V, Aguirre L, et al. Effects of supplemental oxygen during activity in patients with advanced COPD without severe resting hypoxemia. Chest 2001; 120: 437-443.

35 Woodcock AA, Gross ER, Geddes DM. Oxygen relieves breathlessness in 'pink puffers'. Lancet 1981; 317 907-909.

36 McDonald CF, Blyth CM, Lazarus MD, et al. Exertional oxygen of limited benefit in patients with chronic obstructive pulmonary disease and mild hypoxemia. Am J Respir Crit Care Med 1995; 152: 1616-1619.

37 Crisafulli E, Beneventi C, Bortolotti V, et al. Energy expenditure at rest and during walking in patients with chronic respiratory failure: a prospective two-phase case-control study. PLoS One 2011; 6: e23770.

38 Chan ED, Chan MM, Chan MM. Pulse oximetry: understanding its basic principles facilitates appreciation of its limitations. Respir Med 2013; 107: 789-799.

39 Hernandes NA, Wouters EFM, Meijer K, et al. Reproducibility of 6-minute walking test in patients with COPD. Eur Respir J 2011; 38: 261-267. 